\title{
EMERGENCY REMOVAL OF A MOBILE FOREIGN BODY IN A CYANOSED INFANT- A CASE REPORT
}

\author{
Sujata Ghosh', Soma Khan², Chandan Kumar Panda³, Bivas Adhikary, Atish Haldar ${ }^{5}$ \\ ${ }^{1}$ Assistant Professor, Department of Anaesthesiology, Calcutta National Medical College, Kolkata, West Bengal. \\ ${ }^{2}$ Medical Officer, Department of Anaesthesiology, Calcutta National Medical College, Kolkata, West Bengal. \\ ${ }^{3}$ Senior Resident, Department of Anaesthesiology, Calcutta National Medical College, Kolkata, West Bengal. \\ ${ }^{4}$ Associate Professor, Department of Otolaryngology, Calcutta National Medical College, Kolkata, West Bengal. \\ ${ }^{5}$ Assistant Professor, Department of Otolaryngology, Calcutta National Medical College, Kolkata, West Bengal.
}

\section{ABSTRACT}

Foreign body aspiration of tracheobronchial tree is a common medical emergency, but it is unusual in infants. It causes significant morbidity and even with lethal consequences. It poses a great challenge to anaesthesiologist as well as to the ENT surgeon.

\section{REPORT}

We report a case of a mobile foreign body aspirated by an 8-month-old infant presenting with stridor, cyanosis and collapse when placed supine.

\section{CONCLUSION}

Meticulous history and radiographs are essential aids for better management by an anaesthesiologists but times of extreme emergency requires unconventional decisions and unconventional methods to save the life of a child.

\section{KEYWORDS}

Foreign Body Bronchus, Stridor, Cyanosis, Early Resuscitation, Endoscopic Removal.

HOW TO CITE THIS ARTICLE: Ghosh S, Khan S, Panda CK, et al. Emergency removal of a mobile foreign body in a cyanosed infant: a case report. J Evolution Med Dent Sci 2016;5(2):171-172, DOI: 10.14260/jemds/2016/39

\section{INTRODUCTION}

Majority of the otolaryngeal foreign bodies do not pose much anaesthestic challenge during endoscopic removal. However foreign body bronchus always demand an efficient anaesthetic team and often grave complications need to be dealt with unusual measures in order to save the life of the patients. ${ }^{1} \mathrm{We}$ report this case of a foreign body bronchus in an infant as it presented with unusual life-threatening complications. Foreign body bronchus per se is unusual in infants. The tracheobronchial tree is ill- developed in an infant and more often than not these foreign bodies cause varying degrees of obstruction leading to stridor and hypoxia in the infant.

\section{CASE REPORT}

An 8-month-old male infant weighing $5 \mathrm{kgs}$ presented to the Emergency Department with shortness of breath and stridor. The parents gave a history of going to a secondary care hospital for foreign body ingestion where removal of foreign body was attempted but failed. On arrival in the emergency department of our hospital, he was distressed, crying and coughing intermittently. He had stridor, his respiratory rate was 40 breaths per minute with some intercostal and sternal recession. Room air saturation was $95 \%$. An urgent chest Xray was ordered but on lying the baby supine baby became unresponsive all of a sudden and slowly developed cyanosis. The X-ray could not be done and the child was rushed to Operation Theatre for emergency management and bronchoscopy.

Financial or Other, Competing Interest: None.

Submission 21-12-2015, Peer Review 22-12-2015,

Acceptance 02-01-2016, Published 07-01-2016.

Corresponding Author:

Dr. Sujata Ghosh,

Sangam Apartment, Block $B$

Flat No. 203, 405, G. T. Road,

Bally Howrah.

West Bengal, India.

E-mail: dr.sujata444@gmail.com

DOI:10.14260/jemds/2016/39

\section{Early Resuscitation}

Securing the airway of a cyanosed child was of paramount importance. Examination revealed diminished chest wall movement, decreased air entry, $\mathrm{SPO}_{2}$ was $80 \%$ and steadily desaturating no improvement with $\mathrm{O}_{2}$ therapy with face mask Immediately a careful laryngoscopy was done and 3.0 ID ETT uncuffed was introduced and airway was secured. Air entry improved on both side left >right, (Although more on the left). Spo2 gradually improved to $96 \%$ with $\mathrm{O}_{2}$. Cyanosis disappeared and vitals improved. Resuscitation of the baby was equally important since the baby was totally unresponsive. IV access was established. Ringers lactate was started with a microdrip set. Monitors and precordial stethoscope were attached. The baby was anaesthetized using inhalational induction agent sevoflurane $8 \%$ with $\mathrm{O}_{2}$. After achieving adequate depth, $1 \mathrm{ml}(20 \mathrm{mg})$ Topical lignocaine was sprayed around the glottis and vocal cords after removing the ETT. A $0.5 \mathrm{~mm}$ rigid ventilating bronchoscope was introduced into the trachea without further delay.

\section{Anaesthetic Technique \\ Premedication was given with inj. atropine $0.1 \mathrm{mg}$, inj. ondansetron $0.4 \mathrm{mg}$ and inj. dexamethasone $4 \mathrm{mg}$. The baby was maintained on $2 \%$ sevoflurane and $\mathrm{O}_{2}$ delivered through side port of bronchoscope using Paediatric circuit (Jackson- Rees modification of Ayre's T piece). Intermittent dose of ketamine 5mg and Propofol 5mg supplements were given to facilitate removal of foreign body whenever there was any signs of light plane of anaesthesia. \\ Bronchoscopy revealed a cup shaped plastic material with metallic wire lodged in right main bronchus. After $5 \mathrm{mins}$ foreign body was successfully removed by $3^{\text {rd }}$ attempt without injuring the vocal cord and other structures along with bronchoscope. Immediately air entry to the right side improved and $\mathrm{SPO}_{2}$ became $100 \%$. Check bronchoscopy was performed to rule out residual FB. Baby was reintubated with 3.0 ID uncuffed ETT and waited till baby recovered fully.}


After breathing became regular and with adequate tidal volume achieved extubation was done. After proper oral suctioning 02 was given at $2 \mathrm{~L}$ via face mask. The baby was sent to the recovery room after the baby showed good motor movements, regular chest movements, deep and regular breathing, stabilized vitals, $\mathrm{Spo}_{2}$ maintained at $98 \%$ in room air.

\section{Post-operative Care}

The baby was observed for 24 hours in recovery room and check $\mathrm{x}$ ray was performed and discharged on the same day.

\section{DISCUSSION}

Inhaled FB is an important cause of death in children ${ }^{2}$. Fragile pediatric cardiopulmonary status and limited functional residual capacity lead to reduced respiratory reserve, increased shunting and propensity for airway closure. This coupled with the relative increased oxygen consumption lead to rapid hypoxemia when ventilation is sub optimal ${ }^{3}$. However, in absence of or with failure of the bronchoscopic procedure, innovative approaches are to be adopted so as to save a life. An already compromised airway compelled an induction that maintain spontaneous ventilation to minimize the risk of converting a partial proximal obstruction to a complete one, as positive pressure ventilation may drive the FB foreign body further distally. Hence, we preferred maintaining spontaneous ventilation with inhalational agent as the FB was in the bronchus.

Foreign body bronchus is considered a grave condition more so in children as airway complications lead to increased morbidity and mortality. ${ }^{4}$ Rapid diagnosis and prompt and effective resuscitation is the key to good outcome. Respiratory signs such as violent coughing may or may not be present but a silent chest is the most pathognomonic sign of near total obstruction. Initial symptoms in a child may be vague and missed foreign bodies may lead to chest infection, mediastinitis, deep neck abscess and perforation. ${ }^{5}$

Chest X-ray in AP and Lat view remains the standard investigation for the diagnosis of the foreign body.6,7 However, in our case the patient was rushed to the operation room on clinical suspicion alone that on supine position a partially obstructing foreign body converted to a complete obstruction.

A multidisciplinary approach with a team of radiologists, ENT surgeon, anaesthesiologist and sometimes even the Thoracic surgeon is required for the prompt and effective management of a foreign body bronchus. ${ }^{8}$

\section{CONCLUSION}

During handling a compromised airway, flexibility of the approach must be present. The technique applied may not be the best one, but the anaesthesiologist must be prepared to alter the approach according to the demand of the situation. Expertise of personnel, clear clinical plans and familiarity with equipment is the key to success.

\section{REFERENCES}

1. Bittencourt PF, Camargos PA, Scheinmann P, et al. Foreign body aspiration: clinical, radiological findings and factors associated with its late removal. Int J Pediatr Otorhinolaryngol 2006;70:879-84.

2. Sarkar S, Roychoudhury A, Roychoudhury BK. Foreign bodies in ENT in a teaching hospital in Eastern India, Indian Journal of Otolaryngol Head Neck Surg 2010;62:118.

3. James J Grochowski, Brian Hynes. A toddler with a pharyngeal foreign body Canadian Family Physician 2008;54:1695-6.

4. Cangir AK, Tug T, Okten I. An unusual foreign body in the esophagus: Report of a case. Surg Today 2002;32:523-4.

5. Passali D, Morra B. Upper aerodigestive tract foreign body injury prevention: an ENT evidence-based perspective. Acta Otorhinolaryngol Ital 2005;25(Suppl):78.

6. Cervical esophageal perforation with severe mediastinitis due to an impacted dental prosthesis. Dis Esophagus 2002;15:340-4.

7. Metrangolo S, Monetti C, Meneghini L, et al. Eight years' experience with foreign-body aspiration in children: what is really important for a timely diagnosis? J Pediatr Surg 1999;34:1229-31.

8. Harris CS, Baker SP, Smith GA, et al. Childhood asphyxiation by food: a national analysis and overview, JAMA 1984;251:2231-5. 